\title{
Build it Together and They will Come: The Case for Community-based Participatory Research with Military Populations
}

\author{
Ellen R. DeVoe \\ Abigail M. Ross \\ Ruth Paris
}

\begin{abstract}
In this article, we describe the methodology broadly known as communitybased participatory research (CBPR) and identify its relevance to social work intervention research with families serving in Operation Enduring Freedom/Operation Iraqi Freedom (OEF/OIF). Since the inception of OEF/OIF, much has been written about low rates of service utilization among military service members and families to address deployment and combat-related concerns. Barriers to participation include difficulty accessing programs, mistrust of clinicians/researchers, concerns about confidentiality, stigma, and career implications, and perceptions of program effectiveness. Because $C B P R$ values the community's inherent resilience and expertise about its own needs, this method can be important for the development of feasible, culturally-relevant and evidence-based prevention and intervention models for military populations. To illustrate, we provide an overview of our implementation of CBPR to develop and test a home-based reintegration program for military families with very young children. Implications for social work practice and research are discussed.
\end{abstract}

Keywords: Military families, Community-Based Participatory Research, OEF/OIF

\section{INTRODUCTION TO COMMUNITY BASED PARTICIPATORY RESEARCH}

Community-Based Participatory Research (CBPR) is an orientation to the research process rather than a specific methodology or research design. It assumes collaboration between the researcher and the community of interest in all phases of the research process (Viswanathan et al., 2004) and aims to enhance community outcomes and capacity (Minkler \& Wallerstein, 2003). In practical terms, the community actively participates in defining the research questions, aims, and outcomes, rather than serving only as a context and source of data collection and/or a means to further the researcher's goals (Lantz, Israel, Schulz \& Reyes, 2006). Indeed, CBPR as a method emerged from participant action and empowerment strategies developed to respond to marginalized communities that had been prey to "hit and run" research, in which researchers obtained data from a study sample for their own purposes and did not directly or immediately transfer useful or usable knowledge to benefit the community (Franco, McKay, Miranda, Paulino, \& Larwrence, 2007). CBPR is also highly consistent with the current focus on translational research as a cutting-edge priority in developmental prevention and intervention science. Specifically, CBPR not only conforms to the fundamental tenet of translational research,

Ellen R. DeVoe, Ph.D., and Ruth Paris, Ph.D., are associate professors at Boston University School of Social Work, Boston, MA. Abigail M. Ross, MSW, MPH, is project director of Strong Families Strong Forces at Boston University School of Social Work.

Copyright (C) 2012 Advances in Social Work Vol. 13 No. 1 (Spring 2012), 149-165 
to ensure that all findings derived from the research process have "end usability" (Guerra, Graham, \& Tolan, 2011), but prioritizes ongoing researcher collaboration with communities that are intended to benefit from research results. We suggest that CPBR approaches in partnerships between civilian academic researchers and military collaborators can result in timely development of effective prevention and intervention strategies that have strong ecological validity, community buy-in, and relevance to the diverse needs of military families.

In the context of the military community, a CBPR approach views service members, veterans and their families as the experts on their own military-related experiences and struggles who can inform both the research world and service providers of their specific strengths and needs. In our own work as academic researchers, we approach our status as civilian-outsiders from a position of cultural humility, in which we take responsibility for and are committed to a dynamic learning process in which our education about military culture and families is open-ended. The notion of cultural humility is highly consistent with CBPR in that we assume that new knowledge about military families will influence and change the direction of our research and intervention development throughout the research process (Tervalon \& Murray-Garcia, 1998). Our contributions as researchers to the CBPR enterprise include sharing information and securing resources (e.g., grant support) with the community that may not be readily available.

As part of this process, we are responsible for understanding and translating the state of the research regarding the needs of young children in military families and the availability and status of prevention and intervention initiatives targeting this population.

\section{WHAT WE KNOW ABOUT MILITARY FAMILIES WITH VERY YOUNG CHILDREN}

In January 2011, the Obama administration identified military families as an “enduring” priority for the U.S. (President's Commission, 2011) with more than two million troops having served at least one tour in Operation Enduring Freedom and/or Operation Iraqi Freedom. An estimated $55 \%$ of the total Force is married and a substantial number of Active Duty and National Guard/Reserve (NG/R) are parents of dependent children (43.2\% and $41.9 \%$ respectively) (Office of the Deputy Under Secretary of Defense, 2010). Currently, there are approximately 1.9 million children with a military parent. Of children who have experienced at least one parental deployment, those ages birth to 5 years comprise the largest age group (41.5\%), followed by 6-11 year olds (31.2\%), and 12-18 year olds (23.4\%) (Office of the Deputy Under Secretary of Defense, 2010).

War operations in Iraq and Afghanistan have required intense and ongoing involvement by U.S. troops. In fact, the deployment demands of these conflicts are unprecedented in recent history (President's Commission, 2011). The unique characteristics of these "fourth generation" wars (Scott, McCone, \& Mastroianni, 2009), including high operational tempo, ambiguous front lines, ubiquitous enemy, and terrorist tactics have resulted in elevated combat exposure for all troops and increased rates of physical injuries and disabilities specific to contemporary combat strategies (e.g., IEDs, 
roadside bombs, suicide bombs, blast impacts). While the survival rate, enabled by technological advances in medicine, communication, and transportation, is the highest of any war in history, so too are the resulting demands on all systems of care for veterans and their families. The heavy engagement of National Guard/Reserve units in war-related operations as opposed to the more traditional NG/R role in the national emergency response system also represents a significant departure from all earlier conflicts (Council on Social Work Education, 2010) and has important implications for supporting NG/R service members and their families. Specifically, because NG/R families are embedded in the civilian community, they may experience difficulty accessing supports and resources available to deploying or reintegrating families due to geographic dispersal.

Our service delivery systems, both military and civilian, are not yet equipped to respond to the volume and range of concerns within military and veteran populations. For example, although social workers constitute the largest professional discipline serving military communities, the majority of social workers do not receive specialized training through social work curricula in the classroom or field about military culture, the deployment cycle, and war trauma and its impact on families. Furthermore, because $63 \%$ of military families live in diverse communities all over the country (President's Commission, 2011), they are likely being served by community-based agencies including health and mental health clinics, hospitals, schools, and child care agencies that may not be aware of a family's military status or trained to support families who have served. Taken together, the numbers of children, parents, and communities affected, combined with the often urgent and sustained needs resulting from OEF/OIF deployment, separation and combat, necessitate a comprehensive social work response.

Social work is positioned to implement CBPR given the profession's strong foundation in ecologically-based and multi-level practice. Through collaborative research partnerships between social workers and military communities, community-based participatory approaches to prevention and intervention research can expand the profession's capacity to anticipate and offer effective and relevant services for military families. We present our experience in applying a CBPR approach to begin addressing gaps in knowledge about OEF/OIF families with very young children and developing evidence-based interventions to support them.

\section{PARENTING VERY YOUNG CHILDREN DURING DEPLOYMENT AND REINTEGRATION}

Our rationale for focusing on the birth to five year age range is multi-pronged. As noted above, children under age five are disproportionately represented among OEF/OIF families relative to older age groups and are highly vulnerable in the face of prolonged separation from a primary caregiver. While a growing body of literature also has begun to recognize resilience in military families with older children and adolescents (Chandra et al., 2010; Huebner \& Mancini, 2005; MacDermid, Samper, Schwarz, Nishida, \& Nyaronga, 2008), few studies have explored resilience in babies, toddlers, and preschoolers. One study of OEF/OIF children ages 1.5-5 years old during deployment indicates that preschool children of deployed parents were more likely to exhibit increased behavioral symptoms than children in non-deployed families (Chartrand, 
Frank, White, \& Shope, 2008). Infants and toddlers may become more irritable, demonstrate increased vulnerability in sleep disruption, and develop eating problems or separation anxiety in response to at-home caregiver depression, anxiety or parental absence (Lincoln, Swift, \& Shorteno-Fraser, 2008). Discipline problems, increased need for attention, sleep difficulties, confusion, sadness, repeated questioning about the deployed parent, and fear that the deployed parent may not come home may occur in as many as $50 \%$ of children under age five with a parent currently deployed (Blount, Curry, \& Lubin, 1992; Jensen, Martin, \& Watanabe, 1996; Kelley et al., 2001; Rosen, Teitelbaum, \& Westhuis, 1993). The possible effects of deployment on very young children may result in increased and more complicated demands on parents as they work to support their babies, toddlers and preschoolers throughout and after the separation.

We also know that for children of all ages, quality of parenting has emerged consistently as the most robust predictor of adaptive coping and resilience in adverse contexts (Luthar, 2006; Luthar, Sawyer, \& Brown, 2006). The very young child's ability to cope with lengthy separation from a primary caregiver is heavily influenced by how well the at-home caregiver manages the many transitions and challenges inherent throughout the deployment cycle (Chartrand et al., 2008; Cozza, Chun, \& Polo, 2005; Cozza \& Lieberman, 2007; Williams \& Rose, 2007). For the at-home parent with young children, maintaining child care routines and handling expanded responsibilities can be exhausting and may contribute to increased stress levels in children and parents (Kelley et al., 2001). There is also some evidence of increased risk of maltreatment, primarily neglect, during deployment (Gibbs, Martin, Kupper, \& Johnson, 2007; Rentz et al., 2007). These findings suggest that non-deployed parents caring for very young children could benefit from targeted prevention and intervention services throughout the period of deployment separation and beyond.

Post-deployment adjustment presents unique challenges for military families with children under five. Babies and toddlers may not recognize the returning father or mother and often need a period of slow transition to become familiar and comfortable with their service member parent. Routines developed during deployment, such as co-sleeping, may be difficult to disrupt and may be challenged or misunderstood by the reintegrating parent. Toddlers and preschoolers may manifest more separation anxiety in response to either parent's comings and goings (Barker \& Berry, 2009) and can become dysregulated when reminded of the deployment (e.g., when a parent wears his or her uniform for work). While many military families are able to anticipate and weather the strains of the post-deployment period, reintegration becomes more highly fraught when a returning parent is suffering from adverse psychological outcomes such as combat stress, depression, anxiety and/or injury or disability (Huebner, Mancini, Wilcox, Grass, \& Grass, 2007). Recent findings indicating a high prevalence of sub-threshold mental health distress (range from 22-50\% of returning OEF/OIF veterans), in particular partial PTSD, are especially concerning and may substantially compromise parenting in the returning service members (Jakupcak et al., 2007; Pietrzak, Goldstein, Malley, Johnson, \& Southwick, 2009). 


\section{Transition to Parenthood during Deployment}

When a first baby is born during a tour of duty, families grapple with the transition to parenthood in the context of the separation and uncertainty of deployment realities. A service member father's ability to support his partner is clearly constrained by the circumstances of deployment and he is unable to participate instrumentally (e.g., night feedings, etc.) in the daily routine of infant care. On balance, first-time mothers become single parents as they must manage all aspects of parenting without their partner. In our study sample we have been concerned that mothers who give birth to their first baby shortly before or during the separation period may be at greater risk of developing postpartum depression than mothers whose partners are not deployed. This was demonstrated in one study where postpartum depression (PPD) was found at a higher rate in military families as compared to those in the general civilian population (16.9\% vs. 13\%) (Haworth, 2010). For fathers, becoming a parent in absentia can be disorienting and distracting (MacDermid et al., 2005; MacDermid, 2006). Consequently, the returning father must simultaneously reintegrate into the couple relationship, family and community, and move immediately into fatherhood with a baby he does not yet know. Unfortunately, there is very little information about this unique and potentially at-risk subgroup of OEF/OIF parents and the specific challenges they face throughout the deployment cycle.

\section{What is Available?}

Lack of services. Until very recently the Department of Defense and Veteran's Administration (V.A.) have provided a comprehensive array of health and mental health services to the military service member or veteran with the goals of readiness and rehabilitation. Since OEF/OIF, however, there have been important changes in federal policy that focus greater attention to the health and well-being of the totality of U.S. Forces, specifically families of military service members and veterans (Department of Defense Task Force on Mental Health, 2007; Office of the Under Secretary of Defense (Comptroller) CFO, 2010; President's Commission, 2011). While these critical shifts in mandate begin to take root at the level of implementation, the current structure continues to be uneven with both redundancies and significant gaps in services. For OEF/OIF families with very young children, the most basic challenge is the relative absence of developmentally-appropriate and military-sensitive programs in communities. For active duty families and those living on or near installations, the New Parent Support Program within the Family Advocacy umbrella has long been an important resource for new parents through the baby's first year of life; however, for NG/R families living in nonmilitary connected communities and families with babies older than 12 months, such services may not be available or accessible. Additional challenges for families with babies, toddlers and preschoolers can include geographic barriers, difficulties with accessibility (e.g., hours, locations), insurance coverage red-tape, and confusion about eligibility (Gould et al., 2010; Kim, Thomas, Wilk, Castro, \& Hoge, 2010; Pietrzak, Johnson, Goldstein, Malley, \& Southwick, 2009). 


\section{WE BUILT IT SO WHY WON'T THEY COME?}

Top-down vs. bottom-up. The command structure of the U.S. military necessarily relies heavily upon leadership dictating action and directions to lower ranking personnel in support of mission readiness and success. While a top-down strategy is highly effective in the context of war operations, the "ivory-tower" imposition of research agendas and/or mental health expertise on service members and their families has not always been wellreceived and may not be responsive to service members' perceived needs. For example, although there are well-tested evidence-based models of treatment available for service members with mental health concerns, current help-seeking among OEF/OIF veterans remains much lower than documented need (Pietrzak, Johnson et al., 2009; Thomas et al., 2010) despite the fact that the suicide rate in the military reached an all-time high in 2009 (Department of Defense Task Force, 2010). Researchers have identified the specific barriers of negative beliefs about or previous experience with mental health providers (Pietrzak, Johnson et al., 2009; Thomas et al., 2010), and anecdotal evidence indicates that younger service members and veterans may be less likely to use VA-based programs. For NG/R service members, accessibility to existing programs is often a significant barrier. With these considerations in mind, we aimed to build a reintegration program for OEF/OIF families that would eliminate known barriers to participation and help-seeking, including accessibility, stigma, relevance to the military context, and developmental appropriateness. Our particular focus is the NG/R families, who represent a significant but underserved demographic in the ongoing conflicts.

\section{Building it Together: CBPR Case Exemplar}

Strong Families Strong Forces, the program we have been developing, has been working within a CBPR framework since the commencement of our project. As nonmilitary researchers and clinicians funded to develop a program for military families with young children where one parent recently returned from a deployment in Iraq or Afghanistan, we were fully aware of the need to collaborate with military service providers and families in our region. Collectively, the leadership team had both research and clinical experience with trauma, families, and young children. We were very experienced and familiar with evidence-informed and evidence-based models to address traumatic stress and violence-exposure in children, infant mental health, and family therapy prevention and intervention strategies. One team member had substantial familiarity with the Family Advocacy Program and the New Parent Support Program specifically through involvement with an earlier program evaluation effort. Working within a CBPR frame, one of our first tasks was to begin to understand the complexities and needs of the military communities we hoped to support. We anticipated that with the community's expertise combined with our knowledge of existing programs and resources in academia, we could achieve our ultimate goal of creating a viable and effective intervention that would be immediately useful for military families.

\section{Phase One: Doing Our Homework}

We intentionally built into our research plan adequate time and resources to develop our program with the systematic input of military families and health, mental health and 
child/family program providers from both military and civilian services. Consistent with a primary tenet of community collaboration, we endeavored to do our "homework" prior to entering the military community (Franco et al., 2007). More specifically, we immersed ourselves, to the extent possible, in all available sources of information related to OEF/OIF families and context, including conferences, workshops, webinars, and the existing literature. Simultaneously, we conducted extensive outreach to professionals and researchers in diverse systems of care both locally (Veteran's Administration, Family Support Programs, regional Vet Centers, Family Readiness Groups, regional Military Family Life Consultants and child care providers both on base and in the community) and nationally (Director of Psychological Health for the National Guard, National Center for PTSD; Operation Homefront National, Zero to Three National Center for Infants, Toddlers and Families; and the National Military Family Association). Through this intensive process, the breadth of the New England military population was clarified for us. We understood that while there were bases that continued to have smaller active duty components with a range of missions, the largest regional military populations were National Guard members and Reservists from all branches. National Guardsmen and Reservists currently represent approximately $50 \%$ of those serving in the wars in Iraq and Afghanistan and bring needs and strengths distinct from those of active duty units living on or near installations. Given these characteristics, learning the cultures of the NG/R components and the perceived needs of NG/R families with young children became and continues to be a major focus of our work.

To that end, we initiated our formal exploratory work (Phase 1) in which we engaged in countless phone conversations, email exchanges, and ultimately face-to-face meetings and interviews with key informants in our region. We began what is now our strongest collaborative relationship with the National Guard Family Program in Massachusetts (NGFP-MA). Interviews with both military and civilian providers within the NGFP-MA proved to be vital links for our contacts with families and providers in other parts of Massachusetts and other states (e.g. Rhode Island and New Hampshire). In addition, key informant interviews with V.A., mental health, social service and family support personnel deepened our sophistication regarding the needs of military families with young children from the provider perspective. Interviewees shared their perceptions of the challenges facing service members, partners, and children throughout the deployment cycle. They also shared frustration about the services they could not provide even though they could identify the needs. In general, the key informants seemed to view our funding as positive and appreciated the Department of Defense's commitment to developing and testing innovative interventions for military families coping with the strains of deployment. However, these leaders and experts also expressed their appropriate concerns about potential for burden on military families given the explosion of research on the military and considered very carefully whether our involvement with families would be beneficial.

\section{Earning the Trust}

Throughout the process of "doing our homework," we needed to earn the trust of the military community and to demonstrate that we had something to offer. A critical aspect 
of earning the trust of the community has been showing up and spending time in and with the military community and offering full transparency about our intentions and resources (Franco et al., 2007). Specifically, after receiving invitations from our colleagues in the National Guard and Reserve in all branches of the military, we began attending Yellow Ribbon and similar pre and post-mobilization events to share our expertise with respect to young children, parenting and families. We offer briefings on our developing program, the impact of long separations on young children, and parenting guidance focused on both the at-home caregivers and service members. These presentations have been well received and we are often asked to present to a variety of groups, such as those focused on family readiness or veteran's affairs. To give a sense of the intensity of our community involvement, research staff have participated in approximately 140 formal events representing all military components over the course of 28 months. At these same events, and through informal follow-up, we began ongoing conversations with members of the military and support personnel, including chaplains and community organizations among others, who assist service members and their families. Through conversations and shared concerns we continue to build our collaborative network and to deepen our understanding of military families and the providers who support them.

Our initial contacts with service members and their families began at these same pre and post-mobilization events. Through individual exchanges with service members and their families, we described our goal to develop a program for military families with children birth to five and our interest in hearing directly from OEF/OIF service members and partners about their experiences of separation and reintegration. If interested, they were asked to sign a "consent to contact" form, granting us permission to call them, explain the process in greater detail, and ultimately visit them at home for an interview. Service members and partners were offered stipends for their time (where allowed), an essential component to demonstrate the value of their contributions.

In-depth interviews with military families focused on their stories of preparing for deployment, the actual separation, experiences of the service member in theater and of the parent at home with children, communication during the separation, reactions of children to a parent being absent, reunification when the service member returned home, and the reintegration process. We conveyed clearly that we did not have military experience and were not looking for particular answers. Families were willing to share the sometimes ingenious and myriad ways they have coped with the challenges that the deployment and separation presented. For example, we learned of service members calling for snow plows from Iraq, arranging for monthly flowers to be sent to a partner at home, and an at-home parent showing a father (via Skype) his 12 month old baby who was now walking. One mother sent regular care packages to her deployed husband that included a piece of string representing the height of each child so that he could track his children's growth while he was away. We also heard about 4- year olds who wanted to return to a mother's bed, a 2-year old who stopped talking for the duration of deployment, and a toddler who waited by the window for Daddy to come home from work every night for several months after the departure. In this exploratory phase, we listened intently to the array of family experiences and strategies, marveled at their 
abilities to manage the complexities of deployments, and heeded their wishes for supports that could alleviate particular stressors during and post-deployment.

\section{Building the Intervention}

Best practices. While completing interviews with key informants, child care providers, and military families, we simultaneously began developing our intervention. As scholars experienced in research and clinical work with trauma, families, and young children, we searched the literature regarding evidence-informed and evidence-based models that addressed traumatic stress and exposure in children, infant mental health, and family therapy prevention and intervention initiatives. We knew that literature focused on work with military families with young children was not available, but we examined models that had been tested with similar populations using promising strategies. In the infant mental health literature, we looked to the works of Lieberman (Lieberman \& Van Horn, 2005), McDonough (2004), Slade (2005) and Dozier (Dozier, Peloso, Lewis, Laurenceau, \& Levine, 2008), all of whom described interventions for caregivers and young children addressing trauma, separations, and/or attachment concerns. Cohen (Cohen, Mannarino, Berminger, \& Deblinger, 2000) and Scheeringa (Scheeringa et al., 2007) have developed cognitive-behavioral interventions that address frank trauma in children older than three years of age. Lester and her colleagues (2011) developed a family-focused resiliency building program, FOCUS, within the military using evidencebased models as their templates (Beardslee, Gladstone, Wright, \& Cooper, 2003). Although several of the above programs are being adapted currently to work with military families, none except FOCUS was developed with military families in mind.

Existing best and promising practices for both infant mental health and trauma in older children and adolescents are based primarily on the child's victimization or exposure to 'frank' trauma which, in our view, does not characterize a young child's experience of deployment separation. Rather, we take the position that any family experiencing prolonged parent-child separation, including deployment, will be stressed by the experience and that traditional mental health models, typically focused on psychopathology, do not universally apply to military families. For our purposes, we envisioned our program as a universal intervention with preventive as well as therapeutic components focused on the impact of deployment separation and the legacy of warrelated experiences on parenting and parent-child relationships. Our military partners also endorse this view: that a family-focused program would be well received and that access has been an important issue. Furthermore, given our understanding of the impact of separation on the parent-child relationship, we found the work of Slade and colleagues (2005) to be particularly relevant for military families due to the focus on building parental reflective capacity, in this case, about children's experiences of deployment and reintegration.

We also elected, from the beginning, to build a home-based program for OEF/OIF families in part due to the logistical challenges all families with very young children face and with the hope of reducing concerns about stigma and confidentiality. In addition, because our National Guard and Reserve families live in different communities across several states, a home-based model would allow us to serve families who would not 
otherwise be able to access site-based programming. Hence, we were drawn to the homebased interventions described in the literature that tended to focus on the youngest children as viable models and we were hopeful that families in our region would be receptive to a home-based program. With these basic principles-accessibility, familyfocus, building parenting capacities, and awareness of the impact of separation and combat stress - we looked to our key informants and military families to help guide and shape the focus and details of our intervention.

Applying new knowledge from the community to build Strong Families Strong Forces. Our task in building the program was to integrate the diverse contributions of knowledge from the research and practice literatures, our own expertise, and most importantly, the dominant concerns of families we interviewed. The data we collected from our interview participants were replete with details about all aspects of managing one or more deployments. OEF/OIF families' concerns spanned the entire deployment cycle including preparing children during the pre-deployment period, managing children's reactions and supporting communication during the separation, and reintegrating the service member back into family life when s/he returned from theater. Not surprisingly, interview participants shared that there were multiple perspectives on deployment from various family members. We worked to address all major interview themes with an emphasis on honoring each family member's deployment experience over the course of an eight module home-based program that involved the service member, the partner, and the child(ren) under five. Guided by our theoretical grounding in building reflective parenting capacities (Slade, 2005) we strove to focus our program on helping parents understand the emotions, perceptions, behaviors, and needs of their very young children who were too young to share their experiences in words and to encourage the couple to engage in honest discussion about the differences in their deployment narratives.

\section{Phase Two: Piloting Strong Families Strong Forces.}

Throughout the first phase of our research, we continuously vetted plans with our military collaborators through an advisory board and provided feedback about implementation and findings. With substantial support for our ideas and program from Phase 1 families and our collaborators, we moved forward with piloting the intervention with nine military families who had experienced at least one deployment and had a child under five. All nine families completed Strong Families Strong Forces and were given the opportunity to provide substantial and specific feedback about all aspects of the program. Overwhelmingly, families felt helped by the services, comfortable with the members of our team who had met with them weekly for two months, and would recommend the program to other parents in their units. In fact, several pilot families reported that they stood up during drill weekends and at Family Readiness Groups to share their stories of participation in our program and to encourage their fellow service members to consider enrolling. Phase 1 and Pilot families have consistently reported that there was no other program that they knew of, in or out of the military, which addressed the unique issues for families with young children at home. 
This last piece of information presented a particular ethical quandary for us as researchers. We had designed our study as a simple clinical trial to include a treatment group and a control group that would receive "treatment as usual." However, it became clear to us by the end of our pilot that there was no "treatment as usual" for military families with young children in our region. Because our CBPR approach demanded that we incorporate new learning about community needs into the research process, in this case the significant ethical concern of offering no services, we modified the design of our randomized trial to replace "treatment as usual" with a "waitlist control" condition with the option of receiving the program at the end of the wait period. This decision has had significant implications on budget, workload, and study scope because we have now committed to offering the program to any study family who meets eligibility criteria. The change in design was received very positively by our funders and military collaborators as we can now assure that all referred families who so desire will receive our intervention.

\section{Phase Three: Randomized Clinical Trial and Next Steps}

At the time of this writing, we are conducting the randomized clinical trial to test the Strong Families Strong Forces program. On the basis of our pilot and earlier community work, we began our clinical trial with some confidence that our program was feasible and that we would find families to participate. However, we did not expect the level of interest in the program among OEF/OIF families and have been overwhelmed with the volume of potential participants. Surprisingly, we also have not yet had any attrition from the study and had not anticipated that the vast majority of waitlist families would elect to 'opt in' at the end of the waiting period. Though we will not be able to report on the actual effectiveness of the program from a quantitative standpoint until the completion of the trial, we suspect that success in recruitment and retention with the military population stems directly from our CBPR approach. The fact that we teamed with our military collaborators to build our program from the bottom up, that concerns shared by military families became the focus of our work, and that we were willing to bring the program to the participants are a few of the CBPR methods that have contributed to the success of our study thus far. The next significant challenge for our work, if the evidence supports the effectiveness of Strong Families Strong Forces, will be the dissemination of the program model into existing systems of care and across diverse communities where military families live.

\section{Reflections on CBPR Process with Military Partners}

Partnering with the military, especially given our civilian status, during active war operations has presented interesting challenges and opportunities in the CBPR process. In the request for proposals, the Department of Defense discouraged investigators who did not already have existing partnerships with the military from attempting to establish potential collaborative relationships during the proposal preparation stage. This prohibition is unusual, in our experience, in that we could not develop recruitment and sampling strategies nor were we required to propose them until or unless we received funding. As a result, we could not begin our collaborative efforts with military partners 
until our proposal had been recommended for funding. Although we planned specifically for time necessary to begin and consolidate community relationships, gaining approval at all relevant Institutional Review Boards for community outreach proved challenging. A second issue unique to working with the military during active war operations is the tension between the goal of maximum involvement of OEF/OIF families and community collaborators in the research and intervention development process and the realities of war-time demands on our military partners. That is, we understand and respect that military and acute systems needs are necessarily the focus of our collaborators' work. For these reasons, much of the iterative process in refining the Strong Families Strong Forces model has been based on feedback and observations from the families who have participated as opposed to genuine co-authoring of the program manual. Overall, however, our work with and on behalf of OEF/OIF families and their young children has been supported and well-received.

\section{IMPLICATIONS FOR SOCIAL WORK RESEARCH WITH MILITARY COMMUNITIES}

CBPR approaches, especially with military populations, require sustained commitment to community collaboration - which implies time and meaningful presence within the community. Social work researchers who undertake community-based work must expect to engage in an iterative and sustained process of engaging, incorporating and honoring community partners' perspectives and expertise into all aspects of the research enterprise. While we believe that CBPR and similar approaches to research and evaluation lead to more ecologically valid, culturally-relevant and effective interventions, there is not yet mainstream support for and recognition of this kind of work. For many academic researchers, this degree of "leg work" is disadvantageous within the narrow parameters of types of research supported because of the time required to enter a community, collect and analyze data, and publish/disseminate findings. On balance, family members and professionals who support them may feel burdened by researchers who seek knowledge and explore possible collaboration, particularly when they have experienced opportunistic or hit and run researchers in the past. Furthermore, given the protracted length of time from data collection to usable information (e.g., a viable and evidence-based intervention), researchers must be mindful of the current need for immediate services that families and community providers experience. The interests of our partners may not always be well served by participating in collaborative research endeavors. Financial remuneration may be one way to help ameliorate this tension, as providers are always accountable for their time in terms of dollars spent.

CBPR methodology also has been criticized for its lack of rigor, number of (uncontrolled) variables, involvement of "non-experts," the interpretation of qualitative data, and cost-effectiveness, among others. Given the presence of social workers in nearly all services relevant to the care of the military community, social work researchers should be on the forefront of generating new knowledge that can be applied to the development of effective and immediately usable psychosocial and community-based prevention and intervention for OEF/OIF populations. Few evidence-based approaches are available that address the intersecting layers of contemporary military life, family 
systems, and community ecologies in support of OEF/OIF families. Although we are only one case, our preliminary work suggests that community-based participatory approaches may be especially promising toward achieving these goals in social work research.

\section{References}

Barker, L., \& Berry, K. (2009). Developmental issues impacting military families with young children during single and multiple deployments. Military Medicine, 174(10), 1033-1040.

Beardslee, W. R., Gladstone, T. R., Wright, E. J., \& Cooper, A. B. (2003). A familybased approach to the prevention of depressive symptoms in children at risk: Evidence of parental and child change. Pediatrics, 112(2), e119-131.

Blount, B. W., Curry, A., Jr., \& Lubin, G. I. (1992). Family separations in the military. Military Medicine, 157(2), 76-80.

Chandra, A., Lara-Cinisomo, S., Jaycox, L. H., Tanielian, T., Burns, R. M., Ruder, T., et al. (2010). Children on the homefront: The experience of children from military families. Pediatrics, 125(1), 16-25. doi: peds.2009-1180 [pii]10.1542/peds.20091180

Chartrand, M. M., Frank, D. A., White, L. F., \& Shope, T. R. (2008). Effect of parents' wartime deployment on the behavior of young children in military families. Archives of Pediatric and Adolescent Medicine, 162(11), 1009-1014. doi: 162/11/1009 [pii]10.1001/archpedi.162.11.1009

Cohen, J., Mannarino, A., Berminger, L., \& Deblinger, E. (2000). Trauma-focused cognitive behavioral therapy for children and adolescents: An empirical update. Journal of Interpersonal Violence, 15(11), 1202-1223.

Council on Social Work Education. (2010). Advanced Social Work Practice in Military Social Work. Alexandria, VA: Council on Social Work Education.

Cozza, S., Chun, R. S., \& Polo, J. A. (2005). Military families and children during Operation Iraqi Freedom. Psychiatric Quarterly, 76(4), 371-378. doi: 10.1007/s11126-005-4973-y

Cozza, S., \& Lieberman, A. (2007). The young military child: Our modern Telemachus. Zero to Three, 27(6), 27-33.

Department of Defense Task Force. (2010). The Challenge and the Promise: Strengthening the Force, Preventing Suicide and Saving Lives. Final Report of the Department of Defense Task Force on the Prevention of Suicide by Members of the Armed Forces.

Department of Defense Task Force on Mental Health. (2007). An achievable vision: Report of the Department of Defense Task Force on Mental Health. Falls Church, VA: Defense Health Board. 
Dozier, M., Peloso, E., Lewis, E., Laurenceau, J. P., \& Levine, S. (2008). Effects of an attachment-based intervention on the cortisol production of infants and toddlers in foster care. Developmental Psychopathology, 20(3), 845-859.

Franco, L., McKay, M., Miranda, A., Paulino, A., \& Larwrence, R. (2007). Voices from the community: Key ingredients for community collaboration. Social Work in Mental Health, 5(3/4), 313-331.

Gibbs, D. A., Martin, S. L., Kupper, L. L., \& Johnson, R. E. (2007). Child maltreatment in enlisted soldiers' families during combat-related deployments. Journal of the American Medical Association, 298(5), 528-535.

Gould, M., Adler, A., Zamorski, M., Castro, C., Hanily, N., Steele, N., et al. (2010). Do stigma and other perceived barriers to mental health care differ across Armed Forces? Journal of the Royal Society of Medicine, 103(4), 148-156. doi: 103/4/148 [pii]10.1258/jrsm.2010.090426

Guerra, N. G., Graham, S., \& Tolan, P. H. (2011). Raising healthy children: translating child development research into practice. Child Development, 82(1), 7-16. doi: 10.1111/j.1467-8624.2010.01537.x

Haworth. (2010). Incidence and severity of postpartum depression among military beneficiaries. Paper presented at the Postpartum Support International, Pittsburgh, PA.

Huebner, A., \& Mancini, J. (2005). Adjustment among adolescents in military families when a parent is deployed: A final report submitted to the Military Family Research Institute and the Department of Defense Quality of Life Office. Falls Church, VA: Virginia Tech: Department of Human Development.

Huebner, A., Mancini, J., Wilcox, R., Grass, S., \& Grass, G. (2007). Parental deployment and youth in military families: Exploring uncertainty and ambiguous loss. Family Relations, 56(2), 112-122.

Jakupcak, M., Conybeare, D., Phelps, L., Hunt, S., Holmes, H. A., Felker, B., et al. (2007). Anger, hostility, and aggression among Iraq and Afghanistan War veterans reporting PTSD and subthreshold PTSD. Journal of Traumatic Stress, 20(6), 945954. doi: $10.1002 /$ jts.20258

Jensen, P. S., Martin, D., \& Watanabe, H. (1996). Children's response to parental separation during Operation Desert Storm. Journal of the American Academy of Child and Adolescent Psychiatry, 35(4), 433-441.

Kelley, M. L., Hock, E., Smith, K. M., Jarvis, M. S., Bonney, J. F., \& Gaffney, M. A. (2001). Internalizing and externalizing behavior of children with enlisted Navy mothers experiencing military-induced separation. Journal of the American Academy of Child \& Adolescent Psychiatry, 40(4), 464-471.

Kim, P. Y., Thomas, J. L., Wilk, J. E., Castro, C. A., \& Hoge, C. W. (2010). Stigma, barriers to care, and use of mental health services among active duty and National 
Guard soldiers after combat. Psychiatric Services, 61(6), 582-588. doi: 61/6/582 [pii]10.1176/appi.ps.61.6.582

Lantz, P. M., Israel, B. A., Schulz, A. J., \& Reyes, A. (2006). Community-based participatory research: rationale and relevance for social epidemiology. In J. M. Oakes \& J. S. Kaufman (Eds.), Methods in social epidemiology (pp. 239-266). San Francisco, CA: Jossey-Bass.

Lester, P., Mogil, C., Saltzman, W., Woodward, K., Nash, W., Leskin, G., et al. (2011). Families overcoming under stress: Implementing family-centered prevention for military families facing wartime deployments and combat operational stress. Military Medicine, 176(1), 19-25.

Lieberman, A., \& Van Horn, P. (2005). "Don't hit my mommy!" A manual for childparent psychotherapy for young witnesses of family violence. Washington, DC: Zero to Three Press.

Lincoln, A., Swift, E., \& Shorteno-Fraser, M. (2008). Psychological adjustment and treatment of children and families with parents deployed in military combat. Journal of Clinical Psychology, 64(8), 984-992. doi: 10.1002/jclp.20520

Luthar, S. S. (2006). Resilience in development: A synthesis of research across five decades. In D. Cicchetti (Ed.), Developmental psychopathology: Risk, disorder and adaptation (3rd ed., Vol. 2, pp. 739-795). Hoboken, NJ: John Wiley and Sons.

Luthar, S. S., Sawyer, J. A., \& Brown, P. J. (2006). Conceptual issues in studies of resilience: past, present, and future research. Annals of the New York Academy of Sciences, 1094, 105-115. doi: 1094/1/105 [pii]10.1196/annals.1376.009

MacDermid, S., Samper, R., Schwarz, R., Nishida, J., \& Nyaronga, D. (2008). Understanding and promoting resilience in military families Retrieved January 28, 2011, from http://www.mfri.purdue.edu/content/Reports/Understanding\%20and\%20Promoting\% 20Resilience.pdf

MacDermid, S., Schwarz, R., Faber, A., Adkins, J., Mishkind, M., \& Weiss, H. (2005). Military fathers on the front lines. In W. Marsiglio, K. Roy \& G. L. Fox (Eds.), Situated fathering: A focus on physical and social spaces (pp. 209-239). Oxford, UK: Rowman \& Littlefield Publishers.

MacDermid, S. M. (2006). Multiple transitions of deployment and reunion for military families Retrieved January 22, 2007, from http://www.cfs.purdue.edu/mfri/DeployReunion.ppt

McDonough, S. (2004). Interaction guidance: Promoting and nurturing the caregiving relationship. In A. J. Sameroff, S. C. McDonough \& K. L. Rosenblum (Eds.), Treating parent-infant relationship problems: Strategies for intervention (pp. 79-96). New York, NY: The Guilford Press. 
Minkler, M., \& Wallerstein, N. (2003). Introduction to community based participatory research. In M. Minkler \& N. Wallerstein (Eds.), Community based participatory research for health (pp. 3-26). San Francisco, CA: John Wiley \& Sons.

Office of the Deputy Under Secretary of Defense. (2010). 2008 demographics report: A profile of the military community: U.S. Department of Defense.

Office of the Under Secretary of Defense (Comptroller) CFO. (2010). Overview of the United States Department of Defense Fiscal Year 2011 Budget Request: United States Department of Defense.

Pietrzak, R. H., Goldstein, M. B., Malley, J. C., Johnson, D. C., \& Southwick, S. M. (2009). Subsyndromal posttraumatic stress disorder is associated with health and psychosocial difficulties in veterans of Operations Enduring Freedom and Iraqi Freedom. Depress Anxiety, 26(8), 739-744. doi: 10.1002/da.20574

Pietrzak, R. H., Johnson, D. C., Goldstein, M. B., Malley, J. C., \& Southwick, S. M. (2009). Perceived stigma and barriers to mental health care utilization among OEFOIF veterans. Psychiatric Services, 60(8), 1118-1122. doi: 60/8/1118 [pii]10.1176/appi.ps.60.8.1118

President's Commission. (2011). Strengthening Our Military Families: Meeting America's Commitment (pp. 1-23). Washington, DC: The White House.

Rentz, E. D., Marshall, S. W., Loomis, D., Casteel, C., Martin, S. L., \& Gibbs, D. A. (2007). Effect of deployment on the occurrence of child maltreatment in military and nonmilitary families. American Journal of Epidemiology, 165(10), 1199-1206.

Rosen, L. N., Teitelbaum, J. M., \& Westhuis, D. J. (1993). Children's reactions to the Desert Storm deployment: Initial findings from a survey of Army families. Military Medicine, 158(7), 465-469.

Scheeringa, M. S., Salloum, A., Arnberger, R. A., Weems, C. F., Amaya-Jackson, L., \& Cohen, J. A. (2007). Feasibility and effectiveness of cognitive-behavioral therapy for posttraumatic stress disorder in preschool children: Two case reports. Journal of Traumatic Stress, 20(4), 631-636. doi: 10.1002/jts.20232

Scott, W. J., McCone, D. R., \& Mastroianni, G. R. (2009). The deployment experiences of Ft. Carson soldiers in Iraq: Thinking about and training for full-spectrum warfare. Armed Forces \& Society, 35(April), 460-476.

Slade, A. (2005). Reflective parenting programs: Theory and development. Psychoanalytic Inquiry, 640-657.

Tervalon, M., \& Murray-Garcia, J. (1998). Cultural humility versus cultural competence: a critical distinction in defining physician training outcomes in multicultural education. Journal of Health Care for the Poor and Underserved, 9(2), 117-125.

Thomas, J. T., Wilk, J. E., Riviere, L. A., McGurk, D., Castro, C. A., \& Hoge, C. W. (2010). The prevalence of mental health problems and functional impairment among 
active component and national guard soldiers 3 and 12 months following combat in Iraq. Archives of General Psychiatry, 67, 614-623.

Viswanathan, M., Ammerman, A., Eng, E., Garlehner, G., Lohr, K. N., Griffith, D., et al. (2004). Community-based participatory research: assessing the evidence. Evidence Report--Technology Assessment (Summary) (99), 1-8.

Williams, D., \& Rose, T. (2007). I say hello; you say good-bye: When babies are born while fathers are away. [Journal]. Zero to Three, 27(6), 13-19.

\section{Author's note:}

Address correspondence to Professor Ellen DeVoe, Boston University School of Social Work, 264 Bay State Road, Boston, MA 02215. E-mail: edevoe@bu.edu 